\title{
Quantitation of Rate of Gastrointestinal and Buccal Absorption of Acidic and Basic Drugs Based on Extraction Theory
}

\author{
John G. Wagner ${ }^{1,2}$ and Allen J. Sedman ${ }^{1}$ \\ Received Feb. 11, 1972--Final July 17, 1972
}

\begin{abstract}
Equations have been derived which quantitatively describe the rate of gastrointestinal and buccal absorption of acidic and basic drugs as a function of $\mathrm{pH}$ of aqueous lumenal contents and time. The equations have been used to fit observed data in the literature, and the estimated parameters are reported. An equation which describes the renal clearance of an acidic or basic drug as a function of urinary $\mathrm{pH}$ is also derived. In essence, the equations quantitate the $\mathrm{pH}$-partition hypothesis and explain most, if not all, related observed data in the literature. The results suggest that the aqueous diffusion layer may not rate-limit absorption of monomeric drug molecules but that absorption is rate-limited by transfer of drug out of the membrane in vivo.
\end{abstract}

KEY WORDS: rate of absorption; rate of renal reabsorption; extraction theory; partition coefficient in vivo; $p \mathrm{H}$ of lumenal contents.

\section{INTRODUCTION}

Several authors (1-7) have developed equations in an attempt to explain the change in rate of absorption of acidic and basic drugs with change in $p \mathrm{H}$ of the aqueous lumenal contents of the gastrointestinal tract of animals. Analogously, several authors (8-14) have developed equations in an attempt to explain the rate of passive reabsorption of acidic, basic, and neutral drugs from aqueous fluids in the kidney tubules to the renal interstitial fluid and the change in renal clearance of acidic and basic drugs with change in urinary $p \mathrm{H}$.

\footnotetext{
${ }^{1}$ College of Pharmacy and Pharmacy Service, University Hospital, The University of Michigan, Ann Arbor, Michigan.

${ }^{2}$ Address reprint requests to Dr. John G. Wagner, Room W3535, Pharmacy Laboratory, University Hospital, Ann Arbor, Michigan 48104.
} 
For purposes of discussion, $k_{\text {app }}$ is defined as the apparent first-order rate constant for disappearance of total drug from the aqueous fluids of the gastrointestinal lumen, or buccal cavity, or for reabsorption of drug in the kidney tubule. The theory to be presented disregards the aqueous diffusion layer on the lumen side of the membrane and is based on simple extraction theory. The equations derived account for all of the following in quantitative terms: (a) the observed rates of gastrointestinal or buccal absorption, (b) the " $p \mathrm{H}$ shifts" that occur, and (c) the limiting $k_{\mathrm{app}}$ for buccal or gastrointestinal absorption that occurs in a homologous series as the series is ascended. By " $p \mathrm{H}$ shift" is meant that a plot of $k_{\text {app }} v s . p \mathrm{H}$ is shifted to higher $p \mathrm{H}$ values than a plot of fraction of drug which is unionized vs. $p \mathrm{H}$ for an acidic drug, and that a plot of $k_{\text {app }} v$ s. $p \mathrm{H}$ is shifted to lower $p \mathrm{H}$ values than a plot of fraction of drug which is un-ionized $v$ s. $p \mathrm{H}$ for a basic drug. It is shown that the equations derived in this report are capable of fitting $k_{\text {app }} v s$. $p \mathrm{H}$ data which were available in the literature and capable of quantitatively explaining all of the above phenomena. To our knowledge, this is the first time that the parameters of a mathematical model have been directly estimated by fitting $k_{\text {app }} v$ s. $p \mathrm{H}$ data, where the observed $p \mathrm{H}$ values in the lumenal contents or buccal cavity are employed.

\section{THEORY}

Equations for $k_{\mathrm{app}}$ are derived for two different models.

\section{Model A}

Model A assumes that only undissociated molecules transfer from aqueous fluid in the gastrointestinal lumen or buccal cavity into the membrane and out of the membrane into the circulating blood as indicated in scheme I:

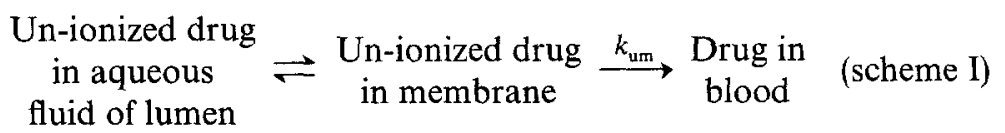

It is assumed that transfer of undissociated molecules through the aqueous diffusion layer on the lumen side of the membrane is much more rapid than transfer of undissociated molecules out of the membrane. Rapid equilibration of undissociated molecules in the aqueous fluids of the lumen with undissociated molecules in the membrane is then consistent with this assumption. There may be an initial lag period before equilibrium occurs, and the equations derived pertain to the condition subsequent to the end of this initial lag period. 
Material balance gives

$$
A_{w}+A_{\text {um }}+A_{b}=D
$$

where $A_{w}$ is the total amount of drug in aqueous fluid of the lumen at time $t, A_{\text {um }}$ is the amount of undissociated molecules in the membrane at time $t$, $A_{b}$ is the amount of drug in the blood at time $t$ (which arose from, but does not necessarily still exist as, undissociated molecules), and $D$ is the total dose of drug introduced into the lumen, and hence is a constant.

Differentiation of equation 1 with respect to time $t$ gives

$$
d A_{\mathrm{w}} / d t+d A_{\mathrm{um}} / d t+d A_{\mathfrak{b}} / d t=0
$$

By definition,

$$
K_{u}=\frac{C_{\mathrm{um}}}{C_{\mathrm{uw}}}=\frac{A_{\mathrm{um}} / V_{m}}{A_{\mathrm{uw}} / V_{w}}=\frac{A_{\mathrm{um}}}{A_{\mathrm{uw}}} \cdot \frac{V_{w}}{V_{m}}
$$

where $K_{u}$ is the intrinsic partition coefficient of undissociated molecules between the membrane and aqueous fluids of the lumen, $C_{u m}$ is the concentration of undissociated molecules in the membrane, $C_{\mathrm{uw}}$ is the concentration of undissociated molecules in aqueous lumenal contents under intrinsic conditions (i.e., $p \mathrm{H} \rightarrow 0$ for a monobasic acid and $p \mathrm{H} \rightarrow 14$ for a monacidic base when $p \mathrm{~K}_{w}=14$ at $24^{\circ} \mathrm{C}$ ), $V_{m}$ is the effective volume of the membrane, and $V_{w}$ is the effective volume of the aqueous fluids of the lumen.

Rearrangement of equation 3 gives equation 4 :

$$
A_{\text {um }}=\left(V_{m} / V_{w}\right) \cdot K_{u} \cdot A_{\text {uw }}
$$

Equation 4 holds under conditions where model $\mathrm{A}$ holds, i.e., negligible back diffusion from blood into the membrane and essentially instantaneous distribution of un-ionized drug between the membrane and the lumen.

By definition,

$$
\begin{aligned}
P_{u} & =\left(V_{m} / V_{w}\right) \cdot K_{u}=\left(V_{m} / V_{w}\right) \cdot\left(C_{\mathrm{um}} / C_{\mathrm{uw}}\right) \\
f_{u} & =C_{\mathrm{uw}} /\left(C_{\mathrm{uw}}+C_{\mathrm{iw}}\right)=C_{\mathrm{uw}} / C_{\mathrm{w}}
\end{aligned}
$$

where $P_{u}$ is the intrinsic partition coefficient which incorporates the phase volume ratio, $f_{u}$ is the fraction of total drug in the aqueous fluid of the lumen which is undissociated, $C_{\mathrm{iw}}$ is the concentration of ionized drug in the aqueous fluid of the lumen, and $C_{w}$ is the total concentration of drug in the aqueous fluid of the lumen.

From equation 6 , one obtains equations 7 and 8 :

$$
\begin{aligned}
& C_{\mathrm{uw}}=f_{u} \cdot C_{w} \\
& A_{\mathrm{uw}}=V_{w} C_{\mathrm{uw}}=f_{u} V_{w} C_{w}=f_{u} A_{w}
\end{aligned}
$$


Substituting from equations 5 and 8 into equation 4 gives

$$
A_{\mathrm{um}}=f_{u} P_{u} A_{w}
$$

Differentiating equation 9 with respect to time yields

$$
d A_{u m} / d t=f_{u} P_{u}\left(d A_{w} / d t\right)
$$

The rationale for equations 9 and 10 is as follows. The undissociated drug is assumed to partition between the aqueous fluid of the lumen and the membrane in much the same manner that a drug partitions between an aqueous buffer and an organic solvent in vitro. Equation 9 expresses the mass balance of this partitioning. It is also assumed that the rate of transfer of undissociated molecules through the bulk aqueous phase and the aqueous diffusion layer on the lumen side of the membrane is so rapid compared with the rate of transfer of undissociated molecules out of the membrane that the rate into the membrane may be ignored. Hence equation 10 may be written.

The $d A_{b} / d t$ of equation 2 represents the rate of appearance of drug in the blood and is given by equation 11 when back diffusion from the blood to the membrane is assumed to be negligible.

$$
d A_{b} / d t=k_{\mathrm{um}} \cdot A_{\mathrm{um}}
$$

where $k_{u m}$ is the first-order rate constant for transport of the undissociated drug out of the membrane.

Substituting from equation 9 into equation 11 gives

$$
d A_{b} / d t=k_{\mathrm{um}} f_{u} P_{u} A_{w}
$$

Substituting from equations 10 and 12 into equation 2 yields

$$
d A_{w} / d t+f_{u} P_{u}\left(d A_{w} / d t\right)+k_{\mathrm{um}} f_{u} P_{u} A_{w}=0
$$

Rearrangement of equation 13 gives

$$
-\frac{d A_{w}}{d t}=\left\{\frac{k_{\mathrm{um}} f_{u} P_{u}}{1+f_{u} P_{u}}\right\} A_{w}
$$

Since

$$
A_{w}=V_{w} \cdot C_{w}
$$

substituting for $A_{w}$ in equation 14 from equation 15 and cancelling the $V_{w}$ 's gives

$$
-d C_{w} / d t=\left\{k_{u m} f_{u} P_{u} /\left(1+f_{u} P_{u}\right)\right\} C_{w}
$$

where

$$
k_{\mathrm{app}}=k_{\mathrm{um}} f_{u} P_{u} /\left(1+f_{u} P_{u}\right)
$$


It should be noted that from equations 2 and 10 one obtains equation 18 :

$$
\frac{d A_{b}}{d t}=-\left[\left(\frac{1+f_{u} P_{u}}{f_{u} P_{u}}\right) \frac{d A_{\mathrm{um}}}{d t}\right]
$$

Equation 18 indicates that in this theory the rate of appearance of drug in the blood is proportional to, but not equal to, the rate of change of amount of drug in the membrane.

Also, let $f_{E}$ be the fraction of the total drug in the aqueous fluids of the lumen which is extracted by the membrane. This is analogous to the $\mathrm{o} / \mathrm{w}$ partitioning of drug between an organic solvent and an aqueous phase in vitro. Then

$$
f_{E}=\frac{V_{w} C_{\mathrm{um}}}{V_{m} C_{\mathrm{um}}+V_{w} C_{\mathrm{uw}}+V_{w} C_{\mathrm{iw}}}=\frac{V_{m} C_{\mathrm{um}}}{V_{m} C_{\mathrm{um}}+V_{w} C_{w}}=\frac{A_{\mathrm{um}}}{A_{\mathrm{um}}+A_{w}}
$$

Substituting for $A_{\text {um }}$ in equation 19 from equation 9 and simplification gives

$$
f_{E}=f_{u} P_{u} /\left(1+f_{u} P_{u}\right)
$$

Substituting from equation 20 into equation 17 yields

$$
k_{\mathrm{app}}=k_{\mathrm{um}} \cdot f_{E}
$$

In the equations above, $f_{u}$ is given by equation 22 for a monobasic acid and by equation 23 for a monoacidic base:

$$
\begin{aligned}
& f_{u}=1 /\left(1+10^{p \mathrm{H}-p \mathrm{~K}_{a}}\right) \\
& f_{u}=1 /\left(1+10^{p \mathrm{~K}_{a}-p \mathrm{H}}\right)
\end{aligned}
$$

More complicated expressions giving $f_{u}$ for dibasic acids, diacidic bases, amphoteric compounds, etc., are readily obtained.

\section{Model B}

Model B assumes that undissociated molecules transfer from aqueous fluid in the gastrointestinal lumen or buccal cavity into the membrane and out of the membrane into the circulating blood as indicated in scheme I for model A. In addition, model B assumes that ionized drug transfers from aqueous fluid in the gastrointestinal lumen or buccal cavity into the membrane and out of the membrane into the circulating blood as indicated in scheme II:

$$
\begin{aligned}
& \text { Ionized drug } \\
& \underset{\text { in aqueous }}{\text { luid of lumen }} \rightleftharpoons \underset{\text { in membrane }}{\text { Ionized drug }} \stackrel{k_{\text {im }}}{\rightarrow} \underset{\text { blood }}{\text { Drug in }} \quad \text { (scheme II) }
\end{aligned}
$$


Material balance gives

$$
A_{\mathrm{w}}+A_{\mathrm{um}}+A_{\mathrm{im}}+A_{b}=D
$$

where $A_{w}, A_{\text {um }}$, and $D$ are as defined above, $A_{\text {im }}$ is the amount of ionized drug in the membrane at time $t$, and $A_{b}$ is the amount of drug in the blood at time $t$ which arose from transport of both undissociated molecules and ions out of the membrane (but the same ratio of molecules to ions need not necessarily exist in blood as in the membrane).

Differentiation of equation 24 with respect to time gives

$$
d A_{w} / d t+d A_{\mathrm{um}} / d t+d A_{\mathrm{im}} / d t+d A_{b} / d t=0
$$

The same assumptions are made with respect to ions as made for undissociated molecules under scheme I above.

By definition,

$$
K_{i}=\frac{C_{\mathrm{im}}}{C_{\mathrm{iw}}}=\frac{A_{\mathrm{im}} / V_{m}}{A_{\mathrm{iw}} / V_{w}}=\frac{A_{\mathrm{im}}}{A_{\mathrm{iw}}} \cdot \frac{V_{w}}{V_{m}}
$$

where $K_{i}$ is the intrinsic partition coefficient of ionized drug between the membrane and aqueous fluid of the lumen, $C_{\mathrm{im}}$ is the concentration of ionized drug in the membrane, and $C_{\mathrm{iw}}$ is the concentration of ionized drug in aqueous lumenal contents under intrinsic conditions (i.e., $p \mathrm{H} \rightarrow 14$ for a monobasic acid and $p \mathrm{H} \rightarrow 0$ for a monoacidic base when $p \mathrm{~K}_{w}=14$ at $24^{\circ} \mathrm{C}$ ).

Rearrangement of equation 26 , and assumptions with respect to ions similar to those made for un-ionized drug above, gives

$$
A_{\text {im }}=\left(V_{m} / V_{w}\right) \cdot K_{i} \cdot A_{\mathrm{iw}}
$$

By definition,

$$
P_{i}=\left(V_{m} / V_{w}\right) \cdot K_{i}=\left(V_{m} / V_{w}\right) \cdot\left(C_{\mathrm{im}} / C_{\mathrm{iw}}\right)
$$

From equation 6 , one obtains

$$
C_{\mathrm{iw}}=\left(1-f_{u}\right) C_{w}
$$

Hence

$$
A_{\mathrm{iw}}=V_{w} C_{\mathrm{iw}}=\left(1-f_{u}\right) V_{w} C_{w}=\left(1-f_{u}\right) A_{w}
$$

Substituting from equations 28 and 30 into equation 27 gives

$$
A_{\text {i m }}=\left(1-f_{u}\right) P_{i} A_{w}
$$

Difierentiating equation 31 with respect to time yields

$$
d A_{\mathrm{im}} / d t=\left(1-f_{u}\right) P_{i}\left(d A_{w} / d t\right)
$$

The rationale for equations 31 and 32 is analogous to the rationale for equations 9 and 10 discussed above under model $A$. 
The $d A_{b} / d t$ in equation 25 represents the rate of appearance of drug in the blood from both undissociated molecules and ions passing out of the membrane and hence is given by equation 33 :

$$
d A_{b} / d t=k_{\mathrm{um}} A_{\mathrm{um}}+k_{\mathrm{im}} A_{\mathrm{im}}
$$

where $k_{\mathrm{im}}$ is the first-order rate constant for transport of ionized drug out of the membrane and the other symbols are as defined above.

Substituting from equations 9 and 31 into equation 33 gives

$$
d A_{b} / d t=k_{\mathrm{um}} f_{u} P_{u} A_{w}+k_{\text {im }}\left(1-f_{u}\right) P_{i} A_{w}
$$

Substituting from equations 10,32 , and 34 into equation 25 gives

$$
\frac{d A_{w}}{d t}+f_{u} P_{u} \frac{d A_{w}}{d t}+\left(1-f_{u}\right) P_{i} \frac{d A_{w}}{d t}+k_{\mathrm{un}} f_{u} P_{u} A_{w}+k_{\mathrm{im}}\left(1-f_{u}\right) P_{i} A_{w}=0
$$

Rearrangement of equation 35 gives

$$
-\frac{d A_{w}}{d t}=\left\{\frac{k_{\mathrm{um}} f_{u} P_{u}+k_{\mathrm{im}}\left(1-f_{u}\right) P_{i}}{1+f_{u} P_{u}+\left(1-f_{u}\right) P_{i}}\right\} A_{w}
$$

Substituting from equation 15 into equation 36 and cancelling the $V_{w}$ 's gives

$$
-\frac{d C_{w}}{d t}=\left\{\frac{k_{\mathrm{um}} f_{u} P_{u}+k_{\mathrm{im}}\left(1-f_{u}\right) P_{i}}{1+f_{\mathfrak{u}} P_{\mathfrak{u}}+\left(1-f_{\mathfrak{u}}\right) P_{i}}\right\} C_{w}
$$

where

$$
k_{\mathrm{app}}=\frac{k_{\mathrm{um}} f_{u} P_{u}+k_{\mathrm{im}}\left(1-f_{u}\right) P_{i}}{1+\hat{f}_{u} P_{u}+\left(1-f_{u}\right) P_{i}}
$$

In equation $38, f_{u}$ for a monobasic acid is given by equation 22 and for a monoacidic base by equation 23 .

For model $\mathrm{B}$, equation 39 gives the fraction of the total drug in the aqueous fluids of the lumen which is extracted by the membrane $\left(f_{E}\right)$; this equation is analogous to equation 19 for Model A:

$$
f_{E}=\left(A_{\mathrm{um}}+A_{\mathrm{im}}\right) /\left(A_{\mathrm{um}}+A_{\mathrm{im}}+A_{w}\right)
$$

Substituting from equations 9 and 31 into equation 39 , followed by simplification, gives

$$
f_{E}=\left[f_{u} P_{u}+\left(1-f_{u}\right) P_{i}\right] /\left[1+f_{u} P_{u}+\left(1-f_{u}\right) P_{i}\right]
$$

The relationship between equations 38 and 40 is at once apparent and of interest. 


\section{Explanation of Various Observed Phenomena by the Equations}

\section{First-Order Absorption}

Equations 17 and 38 indicate that at fixed $p \mathrm{H}$ of lumenal or buccal contents, $k_{\text {app }}$ is a constant. Equations 14, 16, 36, and 37 indicate that at fixed $\mathrm{pH}$ of lumenal or buccal contents disappearance of total drug is apparent first order. Crouthamel et al. (7), Kakemi et al. (15-17), Shore et al. (1), and Hogben et al. (2) have all demonstrated first-order disappearance of total drug from the lumenal contents of animal intestine, and Beckett et al. $(18,19)$ have demonstrated first-order disappearance of total drug from the contents of the buccal cavity in man. Hence the above equations are in conformity with these observations.

Asymptotic Nature of $\mathrm{k}_{\text {app }}$ in a Homologous Series

For an acidic drug, as $p \mathrm{H} \rightarrow 0, f_{u} \rightarrow 1$, and from equations 17 and 38 one obtains equation 41 :

$$
k_{\mathrm{app}} \rightarrow k_{\mathrm{um}} P_{u} /\left(1+P_{u}\right)
$$

For an acidic drug, as $p H \rightarrow 14, f_{u} \rightarrow 0$, and from equation 38 one obtains equation 42 :

$$
k_{\mathrm{app}} \rightarrow k_{\mathrm{im}} P_{i} /\left(1+P_{i}\right)
$$

In the absence of absorption of ions, then from equation 17 , under the same conditions,

$$
k_{\text {app }} \rightarrow 0
$$

For a basic drug, as $p \mathrm{H} \rightarrow 14, f_{u} \rightarrow 1$, and from equations 17 and 38 one obtains equation 41 under these conditions. As $p \mathrm{H} \rightarrow 0, f_{u} \rightarrow 0$, one obtains equation 42 from equation 38 . In the absence of absorption of ions, one obtains equation 43 under these conditions.

In a homologous series, such as the $n$-alkanoic acids, as the series is ascended both the undissociated molecules and the ionized species become more and more lipophilic, hence $K_{u}, P_{u}, K_{i}$, and $P_{i}$ become larger and larger. Hence, for higher members of such a series of acidic compounds, as $p \mathrm{H} \rightarrow 0$ equation 41 reduces to equation 44 :

$$
k_{\text {app }} \rightarrow k_{\text {um }}
$$

Also, as $p H \rightarrow 14$, equation 42 reduces to equation $45:$

$$
k_{\mathrm{app}} \rightarrow k_{\mathrm{im}}
$$

Equation 44 is an entirely different prediction than that made by the equations of Suzuki et al. (4). Those authors' equations predict that as $K_{u}$ increases, 
diffusion through the aqueous diffusion layer, or so-called stagnant water layer, becomes rate-limiting. That the observed $k_{\text {app }}$ does become asymptotic at low $p \mathrm{H}$ values of contents of the buccal cavity as the homologous series of $n$-alkanoic acids is ascended is indicated by the data of Beckett and Moffat (20). Also, their data indicate that for low members of the series, $k_{\text {app }} \rightarrow 0$ as the $p \mathrm{H}$ is progressively increased, but for higher members of the series $k_{\mathrm{app}}$ approaches a limiting value as $p \mathrm{H} \rightarrow 14$. The latter is explained in this theory by equation 42 .

The shape of $k_{\text {app }} v s . p \mathrm{H}$ plots, or plots of percent absorbed in a given time vs. $p \mathrm{H}$, based on data reported by Beckett and Moffat (20) and Crouthamel et al. (7), is readily explained by equations 17 and 38. Equations 41 through 45 are also useful in obtaining preliminary estimates of parameters for digital computer fitting of $k_{\mathrm{app}}, p \mathrm{H}$ data to either equation 17 or equation 38 as shown later under Results.

\section{Asymptotic Nature of $\mathrm{f}_{\mathrm{E}}$}

Equations 20 and 40 indicate that $f_{E}$ becomes asymptotic as $P_{u}$ is increased at any fixed $p \mathrm{H}$. Under conditions used to obtain the intrinsic partition coefficient of the undissociated species in vitro (i.e., $p \mathrm{H} \rightarrow 0$ for an acidic drug and $p \mathrm{H} \rightarrow 14$ for a basic drug), $f_{u}=1$ and equation 20 reduces to equation 46 :

$$
\left(f_{E}\right)_{I}=P_{u} /\left(1+P_{u}\right)
$$

where $\left(f_{E}\right)_{I}$ represents the fraction extracted under intrinsic partition coefficient conditions. Equation 46 indicates that $\left(f_{E}\right)_{I}$ becomes asymptotic as $P_{u}$ increases.

\section{The $\mathrm{pH}$ Shifts}

Equations 17 and 38 readily explain the so-called $p \mathrm{H}$ shift of the $k_{\text {app }}$, $p \mathrm{H}$ profile away from the $f_{u}, p \mathrm{H}$ profile. For an acidic drug, this may be most readily seen by rearranging equation 20 and substituting for $f_{u}$ from equation 22 as follows:

$$
f_{E}=\frac{f_{u} P_{u}}{1+f_{u} P_{u}}=\frac{1}{1+\left(1 / f_{u} P_{u}\right)}=\frac{1}{1+\left[\left(1+10^{p \mathrm{H}-p \mathrm{~K}_{a}}\right) / P_{u}\right]}
$$

Equation 47 is readily rearranged to equation 48 :

$$
p \mathrm{H}=p \mathrm{~K}_{a}+\log \left[P_{u}\left(1 / f_{E}-1\right)-1\right]
$$

Equation 48 indicates that the extraction curve of an acidic drug is shifted to higher $p \mathrm{H}$ values than the $f_{u}$ vs. $p \mathrm{H}$ curve. When $P_{u} \geq 2$ and $f_{E}=0.5$, equation 48 becomes equation 49 :

$$
(p \mathrm{H})_{0.5 E}=p \mathrm{~K}_{a}+\log \left(P_{u}-1\right)
$$


where $(p \mathrm{H})_{0.5 E}$ represents the $p \mathrm{H}$ at which there is $50 \%$ extraction. Equation 49 indicates that the midpoint of the extraction curve and the midpoint of the $f_{u} v s . p \mathrm{H}$ curve (namely, the $p \mathrm{~K}_{a}$ ) are separated by $\log \left(P_{u}-1\right.$ ) units of $p \mathrm{H}$.

For a basic drug, by similar manipulation, one obtains equations 50 and 51 :

$$
p \mathrm{H}=p \mathrm{~K}_{a}-\log \left[P_{u}\left(1 / f_{E}-1\right)-1\right]
$$

When $P_{u} \geq 2$ and $f_{E}=0.5$, equation 50 becomes

$$
(p \mathrm{H})_{0.5 E}=p \mathrm{~K}_{a}-\log \left(P_{u}-1\right)
$$

The relationships expressed in equations 49 and 51 are illustrated in Fig. 1.

It is interesting that equations analogous to, but not the same as, equations 48 through 51 were published by Craig (21) and Golumbic et al.
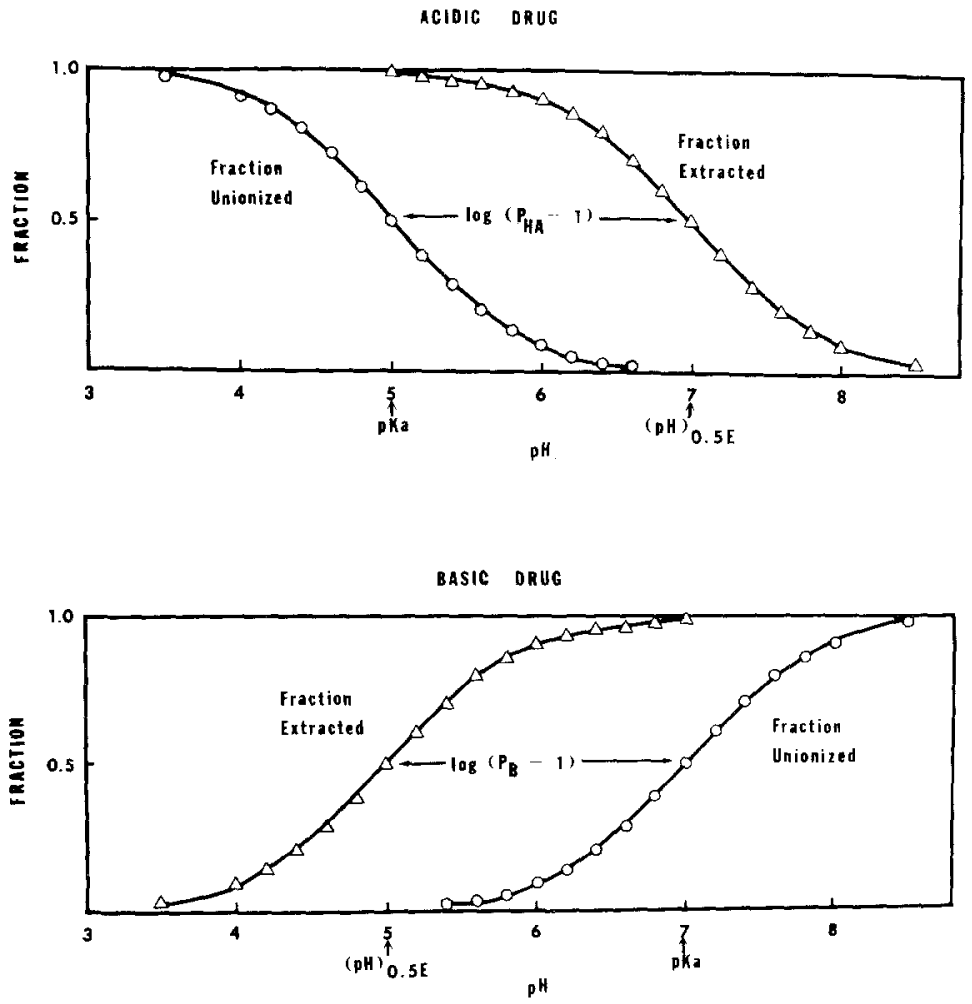

Fig. 1. Plots of fraction extracted and fraction un-ionized against $p \mathrm{H}$ for a monobasic acid and a monoacidic base. The $p \mathrm{H}$ shift shown is based on equations in the text. 
$(22,23)$ in the period 1943 to 1950 before Brodie and coworkers elaborated the $p H$-partition hypothesis $(1,2)$, yet this extraction theory was never incorporated into the latter theory, but may be very pertinent.

Ion absorption also causes an additional shift in the $k_{\text {app }}, p \mathrm{H}$ profile away from the $f_{u}, p \mathrm{H}$ curve in the same direction as discussed above. Hence there are really two factors which contribute to the so-called $p \mathrm{H}$ shifts.

\section{Possible Modification of the Derived Equations}

In special circumstances, equations 16 and 37 will require modification. For amphoteric compounds, dibasic acids, diacidic bases, etc., more than two species may transfer into and out of the membrane. This would lead to more terms in the expressions for $k_{\text {app }}$ than shown in equations 17 and 38. However, the theory could be readily extended to such compounds.

Equations 16 and 37 assume no back diffusion of drug from blood. Since the volumes of distribution of drugs are much larger than the effective volumes of lumenal contents, $C_{w} \gg C_{b}$ during most of the absorption process, where $C_{b}$ is the blood concentration of the drug. However, if the drug were infused intravenously, and at the same time perfused in the lumen of the intestine, as in some of the experiments of Brodie et al. $(1,2)$, then $C_{b}$ may approach or even equal $C_{w}$. Equations 16 and 37 could be modified to cover such conditions, but the modifications made would depend on the assumptions made.

Various other modifications of experimental conditions such as changing luminal contents to hypotonic or hypertonic states or changing buffer capacity of lumenal contents may require modification of the equations. However, the authors also feel that such modification of experimental conditions also probably modifies the properties of the membrane and makes interpretation of data collected in such studies extremely complicated. As applied to data collected in normal animals and man to date under normal physiological conditions, the derived equations appear to explain the observations very well.

\section{Application of the Derived Equations to Reabsorption of Drug in Kidney Tubules}

Equations 17 or 38 should also apply to reabsorption of drugs in the distal tubule of the kidney. Equation 52 is a reasonable expression for the excretion rate of a drug:

$$
\frac{d A_{U}}{d t}=\sigma k_{1} V_{d} C_{P}+\frac{T_{m} C_{P}}{K_{m}+C_{P}}-k_{\mathrm{app}} V_{T} C_{U}
$$

where $d A_{U} / d t$ is the excretion rate of the drug (mass/time), $\sigma$ is the fraction 
of the drug in plasma at the total concentration $\left(C_{P}\right)$ which is free or nonprotein-bound, $k_{1}$ is a first-order rate constant for glomerular filtration (time $\left.{ }^{-1}\right), V_{d}$ is the appropriate volume of distribution for glomerular filtration, $T_{m}$ is the transport maximum (mass/time), $K_{m}$ is the "Michaelis constant" of the transport mechanism (mass/volume), $k_{\text {app }}$ is given by either equation 17 or $38, V_{T}$ is the effective volume of tubule fluid from which reabsorption occurs, and $C_{U}$ is the concentration of drug in the urine. The first term on the right-hand side of equation 52 is the glomerular filtration component, the second term is the transport component, and the third term is the reabsorption component.

The uncorrected renal clearance $\left(R_{c}\right)$ is the excretion rate divided by the total plasma concentration $\left(C_{P}\right)$ and is given by equation 53 :

$$
R_{c}=\frac{d A_{U} / d t}{C_{P}}=\sigma k_{1} V_{d}+\frac{T_{m}}{K_{m}+C_{P}}-k_{\mathrm{app}} V_{T} \cdot \frac{C_{U}}{C_{P}}
$$

If the transport mechanism is in the first-order region (i.e., $K_{m} \gg C_{P}$ ), then equation 53 becomes equation 54 :

$$
R_{c}=V_{d}\left(\sigma k_{1}+k_{2}\right)-k_{\mathrm{app}} V_{T} \cdot\left(C_{U} / C_{P}\right)
$$

where $k_{2}=T_{m}^{\prime} / K_{m}$ and $T_{m}^{\prime}=T_{m} / V_{d}$.

Equations 53 and 54 predict that a plot of $R_{c} v s$. $p \mathrm{H}$ for an acidic drug will have a skewed S-shape. At low urine $p \mathrm{H}, k_{\text {app }}$ will be large, the reabsorption contribution will be large, and $R_{c}$ will be small. As the $p \mathrm{H}$ is progressively raised, $R_{c}$ will increase curvilinearly. When urine $p \mathrm{H}$ is high, $k_{\text {app }}$ will be small, the reabsorption contribution will be small, and $R_{c}$ will asymptotically approach the value $V_{d}\left(\sigma k_{1}+k_{2}\right)$. Davis and Smith (24) and Levy et al. (25) published data giving the renal clearance of salicylate as a function of urine $p \mathrm{H}$. The curves have a similar shape to that predicted above.

A plot of $R_{c}$ vs. urine $p H$ for a basic drug would be expected to have a skewed inverted S-shape based on equations 53 and 54 . At low urine $p \mathrm{H}$, $k_{\text {app }}$ will be small, the reabsorption component will be small, and $R_{c}$ will be large and approach the asymptotic value of $V_{d}\left(\sigma k_{1}+k_{2}\right)$. As the $p \mathbf{H}$ of urine is progressively raised, $R_{c}$ will decrease curvilinearly. When the urine $p \mathrm{H}$ is high, $k_{\text {app }}$ will be large, the reabsorption contribution will be large, and $R_{c}$ will be small.

\section{EXPERIMENTAL}

Fitting of Observed $\boldsymbol{k}_{\text {app }}, \boldsymbol{p} \mathrm{H}$ Data to Model A

Buccal Absorption of Ortho-, Meta-, and Paratoluic Acids in Man

Beckett and Moffat (20) presented a graph of percent absorbed in 5 min against observed $p \mathrm{H}$ of buccal contents for the ortho-, meta-, and 
paratoluic acids in man. The data resulted from application of their buccal absorption test. Beckett kindly supplied the senior author the numerical values which were plotted on their graph. The values of "percent absorbed in 5 min" were converted to $k_{\text {app }}$ values by means of equation 55 :

$$
k_{\mathrm{app}}=\frac{-[\ln 1-(\% \text { absorbed } / 100)]}{5 \times 60} \times 10^{3}
$$

where $k_{\text {app }}$ has dimensions of $\sec ^{-1} \times 10^{3}$. The $k_{\mathrm{app}}, \mathrm{pH}$ values thus obtained for the three acids were simultaneously fitted to equations 17 and 22 by the method of least squares using the program NONLIN and an IBM 360/67 digital computer.

Buccal Absorption of $C_{4}$ Through $C_{8}$ n-Alkanoic Acids in Man

Beckett and Moffat (20) presented a graph of percent absorbed in 5 min against observed $p \mathrm{H}$ of buccal contents for the $\mathrm{C}_{4}$ through $\mathrm{C}_{12} n$-alkanoic acids in man. Beckett kindly supplied the senior author the numerical values which were plotted on the graph. The values of "percent absorbed in 5 min" were converted to $k_{\text {app }}$ values by means of equation 55 . These data were divided into two groups: (a) one for the $\mathrm{C}_{4}$ through $\mathrm{C}_{8}$ acids and (b) the other for the $\mathrm{C}_{9}$ through $\mathrm{C}_{12}$ acids. The reasons for these groupings were as follows. First, it was desirable to test the fit of the data for the $\mathrm{C}_{4}$ through $\mathrm{C}_{8}$ acids to both models $\mathrm{A}$ and $\mathrm{B}$, since, although ion absorption was suspected, the magnitude of the ion absorption relative to the absorption of the un-ionized molecules was relatively small. Second, the data for the $\mathrm{C}_{9}$ through $\mathrm{C}_{12}$ acids could not be fitted by electronic calculator at all well to model $\mathrm{A}$, hence least-squares fitting was only attempted to model $\mathrm{B}$. Third, a simultaneous least-squares fit of the data for all acids $\left(\mathrm{C}_{4}\right.$ through $\mathrm{C}_{12}$ ) to model $\mathrm{B}$ was not feasible with the program NONLIN, since there would be 21 parameters to estimate and the program allows only 16 parameters to be estimated.

The $k_{\text {app }}, p \mathrm{H}$ values for the five $n$-alkanoic acids, $\mathrm{C}_{4}$ through $\mathrm{C}_{8}$, were simultaneously fitted to model $A$ (equations 17 and 22) by the method of least squares using the program NONLIN and an IBM 360/67 digital computer.

\section{Fitting of Observed $k_{\text {app }}, p \mathrm{H}$ Data to Model B}

Buccal Absorption of $C_{4}$ Through $C_{12} \mathrm{n}$-Alkanoic Acids in Man

As explained above, two simultaneous fittings of $k_{\mathrm{app}}, p \mathrm{H}$ data were made to equations 22 and 38 , one employing the data for the $\mathrm{C}_{4}$ through $\mathrm{C}_{8}$ acids and the other employing the data for the $\mathrm{C}_{9}$ through $\mathrm{C}_{12}$ acids. The method of fitting was as described above. 
Gastrointestinal Absorption of Barbital and Sulfaethidole in Rat Intestine

The $k_{\text {app }}$ and lumenal $p \mathrm{H}$ values for absorption of barbital and sulfaethidole in the rat small intestine, reported by Crouthamel et al. (7), were fitted to equations 22 and 38 individually by the method described above. Before fitting, the $k_{\mathrm{app}}$ values with dimensions $\min ^{-1}$ were converted to $\mathrm{hr}^{-1}$ for scaling purposes.

\section{RESULTS}

\section{Buccal Absorption of Ortho-, Meta-, and Paratoluic Acids in Man}

Figure 2 shows the results of the simultaneous fitting of the three sets of data to model A (equations 17 and 22). The lines drawn through the points are the model-predicted $k_{\text {app }}$ values, namely, $k_{\text {app }}$, based on the estimated parameters shown in Table I. The standard deviations of the estimated parameters, shown in Table I, were calculated by means of equation 56 :

$$
\mathrm{SD}=\sqrt{\Sigma \operatorname{dev}^{2} /\left(N-P_{*}\right) \cdot C_{i i}}
$$

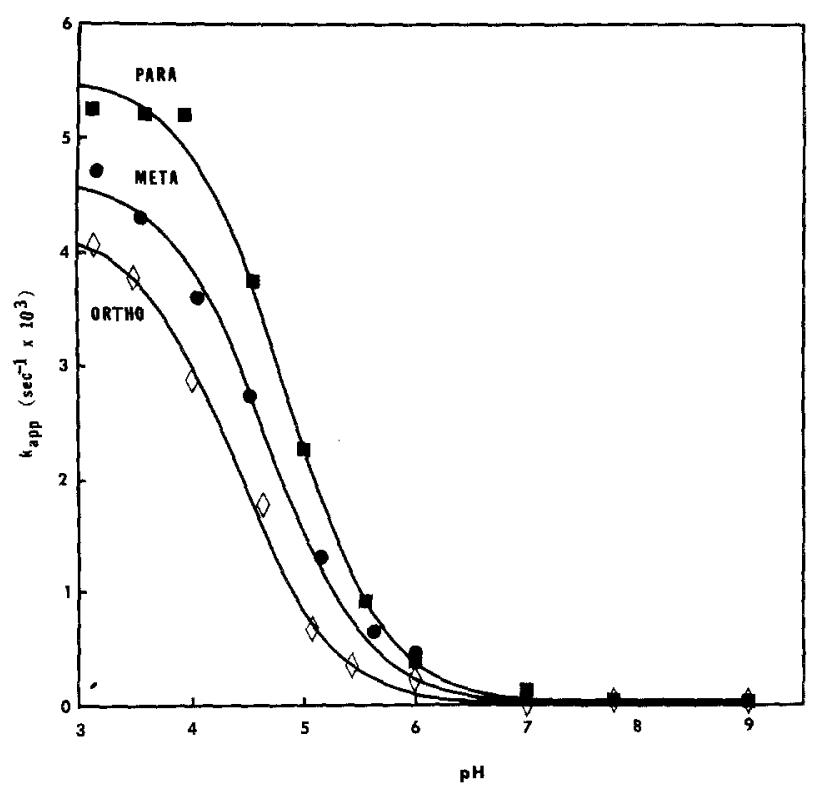

Fig. 2. Fit of the $k_{\text {app }}, p \mathrm{H}$ data of Beckett and Moffat (20) for buccal absorption of ortho-, meta-, and paratoluic acids to model A, based on the parameters shown in Table I. 
Table I. Estimated Parameters and Measures of Fit for Simultaneous Nonlinear Least-Squares Fitting of $k_{\mathrm{app}}, p \mathrm{H}$ Data ${ }^{a}$ for Buccal Absorption of Ortho-, Meta-, and Paratoluic Acids in Man to Model A (Equations 17 and 22)

\begin{tabular}{|c|c|c|}
\hline Parameter & Estimate & $\mathrm{SD}^{b}$ \\
\hline$k_{\mathrm{um}}\left(\mathrm{sec}^{-1} \times 10^{3}\right)$ & 7.48 & 1.33 \\
\hline (ortho & 1.30 & 0.519 \\
\hline$P_{n}\{$ meta & 1.66 & 0.778 \\
\hline para & 2.81 & 1.86 \\
\hline Sortho & 4.04 & 0.115 \\
\hline$p \mathrm{~K}_{a}\{$ meta & 4.26 & 0.123 \\
\hline Lpara & 4.27 & 0.224 \\
\hline \multicolumn{3}{|c|}{ Measures of fit } \\
\hline$r_{1}^{2 c}$ & \multicolumn{2}{|c|}{0.998} \\
\hline$r_{2}^{2 d}$ & \multicolumn{2}{|c|}{0.996} \\
\hline Corr. $^{e}$ & \multicolumn{2}{|c|}{0.998} \\
\hline
\end{tabular}

${ }^{a} k_{\text {app }}$ values were calculated by means of equation 55 from values of percent absorbed in 5 min, kindly supplied by Beckett as data plotted in Fig. 5A of the paper of Beckett and Moffat (20).

${ }^{b}$ Standard deviation of estimated parameter. Since there were 27 data points and seven parameters were estimated, there were 20 degrees of freedom. $c^{2} r_{1}^{2}=\left[\Sigma k_{\text {app }}^{2}-\Sigma\left(k_{\text {app }}-k_{\text {app }}\right)^{2}\right] / \Sigma k_{\text {app }}^{2}$.

${ }^{d} r_{2}^{2}=\left[\mathbf{S} k_{\mathrm{app}}{ }^{2}-\Sigma\left(k_{\mathrm{app}}-k_{\mathrm{app}}\right)^{2}\right] / \mathbf{S} k_{\mathrm{app}}{ }^{2} \quad$ where $S k_{\text {app }}^{2}=\Sigma k_{\text {app }}^{2}-\left(\Sigma k_{\text {app }}^{2}\right) / N$ and $N$ is the number of data points.

${ }^{e}$ The correlation coefficient for the linear regression of $k_{\text {app }} v s . k_{\mathrm{app}}$.

In equation $56, \Sigma \mathrm{dev}^{2}$ is the sum of the squared deviations, i.e., $\Sigma\left(k_{\text {app }}-k_{\text {app }}\right)^{2}$, $N$ is the number of data points, $P_{*}$ is the number of parameters estimated, and $C_{i i}$ is the $i$ th diagonal element of the variance-covariance matrix of estimates. In this fitting, $N=27$ and $P_{*}=7$, hence the number of degrees of freedom, namely, $N-P_{*}$, is 20 . Three different measures of fit are also given in Table I; these are $r_{1}^{2}, r_{2}^{2}$, and Corr.; they were calculated as shown in the footnotes to Table I. The standard deviations are small relative to the magnitude of the estimated parameters, and all three measures of fit are very close to unity, indicating excellent agreement of the observed data to the theoretical model $\mathrm{A}$.

\section{Buccal Absorption of $\boldsymbol{n}$-Alkanoic Acids in Man}

Figure 3 shows the results of both the simultaneous fitting of the data for the $\mathrm{C}_{4}$ through $\mathrm{C}_{8}$ acids and the simultaneous fitting of the data for the 


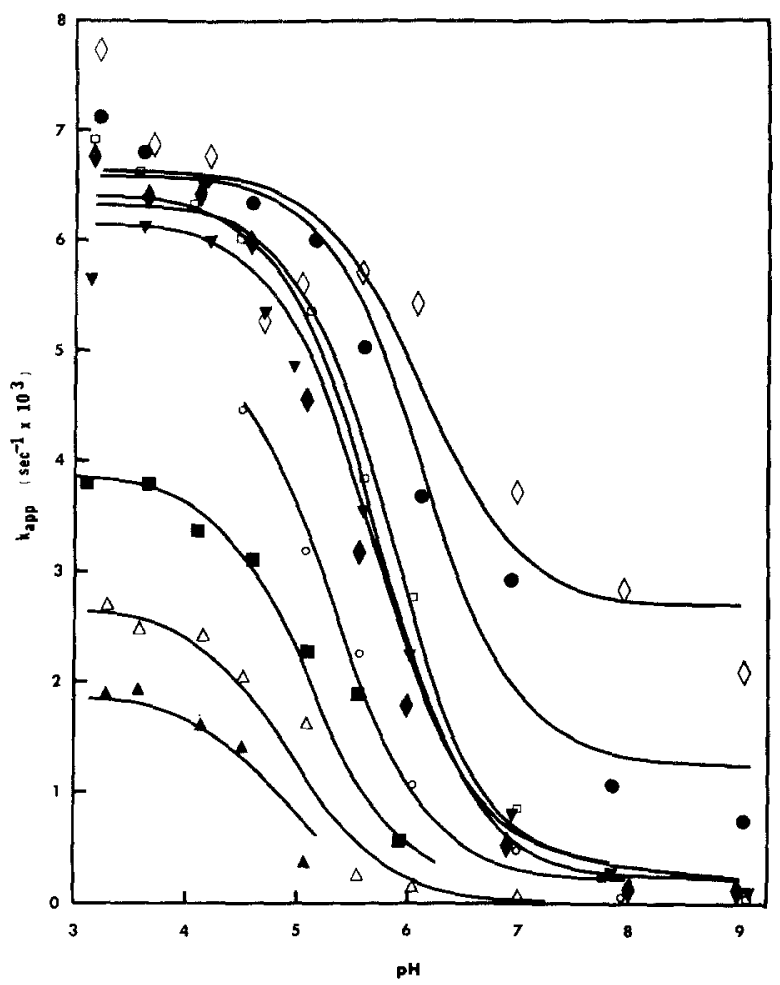

Fig. 3. Fit of the $k_{\text {app }}, p \mathrm{H}$ data of Beckett and Moffat (20) for buccal absorption of the $\mathrm{C}_{4}$ through $\mathrm{C}_{12}$ n-alkanoic acids to model $\mathrm{B}$, based on the parameters shown in Tables II and III. Key: $\Delta, \mathrm{C}_{4} ; \triangle, \mathrm{C}_{5} ; \boldsymbol{\square}, \mathrm{C}_{6} ; \mathrm{O}, \mathrm{C}_{7} ; \bullet, \mathrm{C}_{8} ; \nabla, \mathrm{C}_{9} ; \square, \mathrm{C}_{10}$; $0, \mathrm{C}_{11} ;$ and $\diamond, \mathrm{C}_{12}$.

$\mathrm{C}_{9}$ through $\mathrm{C}_{12}$ acids to model $\mathrm{B}$ (equations 22 and 38). The lines drawn through the points are the model-predicted $k_{\text {app }}$ values, based on the parameters listed under model $\mathrm{B}$ in Table II for the $\mathrm{C}_{4}$ through $\mathrm{C}_{8}$ acids and those listed in Table III for the $\mathrm{C}_{9}$ through $\mathrm{C}_{12}$ acids. The parameters estimated for the $\mathrm{C}_{4}$ through $\mathrm{C}_{8}$ acids using model $\mathrm{A}$ are also listed in Table II, but the results are not shown graphically.

\section{Incremental Partition Coefficients for Buccal Absorption of $\boldsymbol{n}$-Alkanoic Acids in Man}

As Ho and Higuchi (5) pointed out, one can calculate an incremental coefficient $(n)$ from the partition coefficients of $n$-alkanoic acids differing by one methylene group. The parameter $P_{u}$ is the intrinsic partition coefficient of the un-ionized acid multiplied by the phase volume ratio (see equation 5). However, when one determines the ratio of two $P_{u}$ values, the phase volume 
Table II. Estimated Parameters and Measures of Fit for Simultaneous Nonlinear Least-Squares Fitting of $k_{\mathrm{app}}, p \mathrm{H}$ Data ${ }^{a}$ for Buccal Absorption of the $\mathrm{C}_{4}$ Through $\mathrm{C}_{8} n$-Alkanoic Acids in Man to Model A (Equations 17 and 22) and Model B (Equations 22 and 38)

\begin{tabular}{|c|c|c|c|c|}
\hline \multirow{2}{*}{ Parameter } & \multicolumn{2}{|c|}{ Model $A^{b}$} & \multicolumn{2}{|c|}{ Model $B^{c}$} \\
\hline & Estimate & $\mathrm{SD}^{d}$ & Estimate & $\mathrm{SD}$ \\
\hline$k_{\mathrm{um}}\left(\mathrm{sec}^{-1} \times 10^{3}\right)$ & 7.00 & 0.385 & 7.12 & 0.660 \\
\hline$k_{\mathrm{im}}\left(\sec ^{-1} \times 10^{3}\right)$ & - & - & 4.38 & 74.2 \\
\hline$p \mathrm{~K}$ & 4.60 & 0.151 & 4.74 & 0.219 \\
\hline $\mathrm{C}_{4}$ & 0.390 & 0.0837 & 0.359 & 0.0718 \\
\hline$C_{5}$ & 0.6375 & 0.132 & 0.601 & 0.119 \\
\hline$P_{u}\left\{\mathrm{C}_{6}\right.$ & 1.75 & 0.441 & 1.21 & 0.361 \\
\hline $\mathrm{C}_{7}$ & 6.00 & 2.25 & 2.76 & 1.64 \\
\hline$\left(C_{8}\right.$ & 13.5 & 5.92 & 9.02 & 7.15 \\
\hline $\mathrm{C}_{4}$ & - & - & 0.0000735 & 0.00266 \\
\hline $\mathrm{C}_{5}$ & - & - & 0.00633 & 0.108 \\
\hline$P_{i}\left\{\mathrm{C}_{6}\right.$ & - & - & 0.0409 & 0.785 \\
\hline $\mathrm{C}_{7}$ & - & - & 0.0523 & 0.960 \\
\hline$C_{8}$ & 一 & - & 0.0523 & 0.943 \\
\hline \multicolumn{5}{|c|}{ Measures of fit ${ }^{d}$} \\
\hline$r_{1}^{2}$ & \multicolumn{2}{|c|}{0.980} & \multicolumn{2}{|c|}{0.991} \\
\hline$r_{2}^{2}$ & \multicolumn{2}{|c|}{0.950} & \multicolumn{2}{|c|}{0.976} \\
\hline Corr. & \multicolumn{2}{|c|}{0.982} & \multicolumn{2}{|c|}{0.988} \\
\hline
\end{tabular}

${ }^{a} k_{\text {app }}$ values were calculated by means of equation 55 from values of percent absorbed in 5 min, kindly supplied by Beckett as data plotted in Fig. 4 of the paper of Beckett and Moffat (20).

${ }^{b}$ Since there were 36 data points and seven parameters, there were 29 degrees of freedom.

'Since there were 36 data points and 13 parameters, there were 23 degrees of freedom.

${ }^{d S}$ See footnotes to Table I.

ratio cancels. Hence the ratio of $P_{u}$ values is equivalent to the ratio of intrinsic partition coefficients for the two acids between the membrane and the aqueous contents of the buccal cavity. This is indicated by equation 57 :

$$
n=\frac{\left(P_{u}\right)_{j+1}}{\left(P_{u}\right)_{j}}=\frac{\left(V_{m} / V_{w}\right) K_{j+1}}{\left(V_{m} / V_{w}\right) K_{j}}=\frac{K_{j+1}}{K_{j}}
$$

where $j$ and $j+1$ are the carbon numbers of two $n$-alkanoic acids differing by one methylene group. The values of $n$ which were calculated by application of equation 57 are shown in Table IV. The average value of $n$ calculated for the $\mathrm{C}_{4}$ to $\mathrm{C}_{8}$ acids by this method and for model $\mathrm{B}$ is 2.31. Applying their aqueous diffusion layer model, Ho and Higuchi (5) reported an average value of 2.33 using the same method and for the same acids. Hence the two entirely different models yield the same average value of $n$ for these five 
Table III. Estimated Parameters and Measures of Fit for Simultaneous Nonlinear Least-Squares Fitting of $k_{\mathrm{app}}, p \mathrm{H} \mathrm{Data}^{a}$ for Buccal Absorption of the $\mathrm{C}_{9}$ Through $\mathrm{C}_{12}$ n-Alkanoic Acids in Man to Model B (Equations 22 and 38)

\begin{tabular}{|c|c|c|}
\hline Parameter & Estimate $^{b}$ & $\mathrm{SD}^{c}$ \\
\hline $\begin{array}{l}k_{\text {urst }}\left(\mathrm{sec}^{-1} \times 10^{3}\right) \\
k_{\text {im }}\left(\sec ^{-1} \times 10^{3}\right) \\
p \mathrm{~K}_{a}\end{array}$ & $\begin{array}{l}6.78 \\
6.95 \\
4.67 \\
10.0 \\
15.0 \\
34.7 \\
45.0 \\
0.0524 \\
0.0344 \\
0.214 \\
0.634\end{array}$ & $\begin{array}{l}0.345 \\
6.22 \\
0.367 \\
7.61 \\
12.5 \\
32.5 \\
44.2 \\
0.0640 \\
0.0539 \\
0.247 \\
0.947\end{array}$ \\
\hline \multicolumn{3}{|c|}{ Measures of $\mathrm{fit}^{\mathrm{c}}$} \\
\hline $\begin{array}{l}r_{1}^{2} \\
r_{2}^{2} \\
\text { Corr. }\end{array}$ & $\begin{array}{l}0.992 \\
0.965 \\
0.983\end{array}$ & \\
\hline
\end{tabular}

${ }^{a}$ See footnote $a$ to Table II.

${ }^{b}$ Since there were 40 data points and 11 parameters, there were 29 degrees of freedom.

'See footnotes to Table I.

$n$-alkanoicacids. The average value of $n$ for the same five acids, when evaluated by model A, gave the slightly higher value of 2.48 .

The calculation of individual values of $n$ from the $P_{u}$ values of pairs of $n$-alkanoic acids differing by one carbon atom is subject to variation due to errors in both of the $P_{u}$ values. The value of $n$ may be estimated from all the $P_{u}$ values simultaneously by application of equations 58 and 59:

$$
\begin{aligned}
P_{u} & =a \cdot n^{c} \\
\log P_{u} & =\log a+(\log n) \cdot C
\end{aligned}
$$

In equations 58 and $59, a$ is a constant and $C$ is the carbon number of the acid. In conformity with equation 59 , the $P_{u}$ values of the $\mathrm{C}_{4}$ to $\mathrm{C}_{12} n$-alkanoic acids, evaluated by model $\mathrm{B}$, are plotted semilogarithmically against the carbon number of the acid in Fig. 4. Using all nine points, the least-squares line had an intercept of $\log a=-1.5027$, whence $a=0.0314$, and a slope of $\log n=0.2737$, whence $n=1.88$; the correlation coefficient was 0.988 . Since the $P_{u}$ value for the $\mathrm{C}_{8}$ acid departed considerably from the trend of the other points, the least-squares line was also estimated for eight points (excluding the $P_{u}$ value for the $\mathrm{C}_{8}$ acid). The latter line had an intercept of 
Table IV. Incremental Partition Coefficients for Unionized Molecules of $n$-Alkanoic Acids in the Buccal Absorption Test

\begin{tabular}{lcc}
\hline & \multicolumn{2}{c}{$n$} \\
\cline { 2 - 3 } Acids & Model A & Model B \\
\hline $\mathrm{C}_{5} / \mathrm{C}_{4}$ & 1.63 & 1.67 \\
$\mathrm{C}_{6} / \mathrm{C}_{5}$ & 2.75 & 2.01 \\
$\mathrm{C}_{7} / \mathrm{C}_{6}$ & 3.43 & 2.28 \\
$\mathrm{C}_{8} / \mathrm{C}_{7}$ & 2.10 & 3.27 \\
$\mathrm{C}_{9} / \mathrm{C}_{8}$ & - & 1.11 \\
$\mathrm{C}_{10} / \mathrm{C}_{9}$ & - & 1.50 \\
$\mathrm{C}_{11} / \mathrm{C}_{10}$ & - & 2.31 \\
$\mathrm{C}_{12} / \mathrm{C}_{11}$ & - & 1.30 \\
Average of $\mathrm{C}_{4}$ to $\mathrm{C}_{8}$ & 2.48 & 2.31 \\
Average of $\mathrm{C}_{4}$ to $\mathrm{C}_{12}$ & - & 1.93 \\
\hline
\end{tabular}

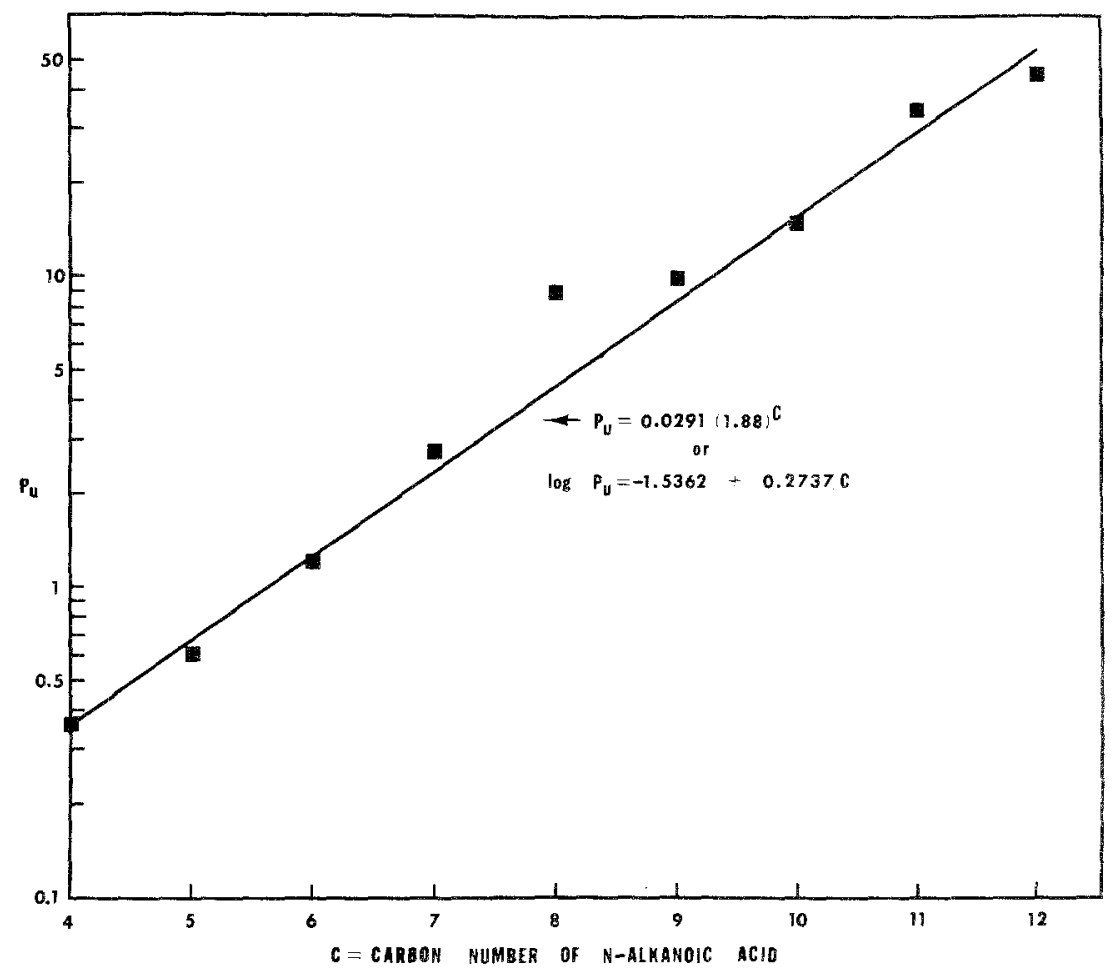

Fig. 4. Semilogarithmic plot of $P_{\mu}$ against carbon number of $n$-alkanoic acid when data are evaluated by model $B$. 
$\log a=-1.5362$, whence $a=0.0291$, and a slope of $\log n=0.2737$, whence $n=1.88$; the correlation coefficient was 0.997 . The second line is the one drawn through the points in Fig. 4.

The incremental partition coefficient of 1.88 implies that the membrane of the buccal cavity is not strongly nonpolar. Ho and Higuchi (5) point out (a) that the butanol/water system would probably yield a value near 2.3 at $37^{\circ} \mathrm{C}$ and (b) that incremental constants from 1.7 to 2.5 per unshielded $\mathrm{CH}_{2}$ group among chosen homologous pairs of ether, alcohol, amide, and ester molecules have been reported from permeation determinations using the plant cell Chara ceratophylla.

\section{Gastrointestinal Absorption of Barbital and Sulfaethidole in Rat Intestine}

Figure 5 shows the results of the individual fittings of the $k_{\text {app }}, p \mathrm{H}$ data for barbital and sulfaethidole in rat small intestine. The lines drawn through the points are the model-predicted $k_{\text {app }}$ values based on the parameters shown in Table V. In these two cases, the measures of fit $r_{1}^{2}, r_{2}^{2}$, and Corr. are close to unity, but the standard deviations are excessive relative to the magnitude of the estimates. This is not really a reflection of poor fits to the model, but rather mainly a reflection of the fact that there were only 4 and 5

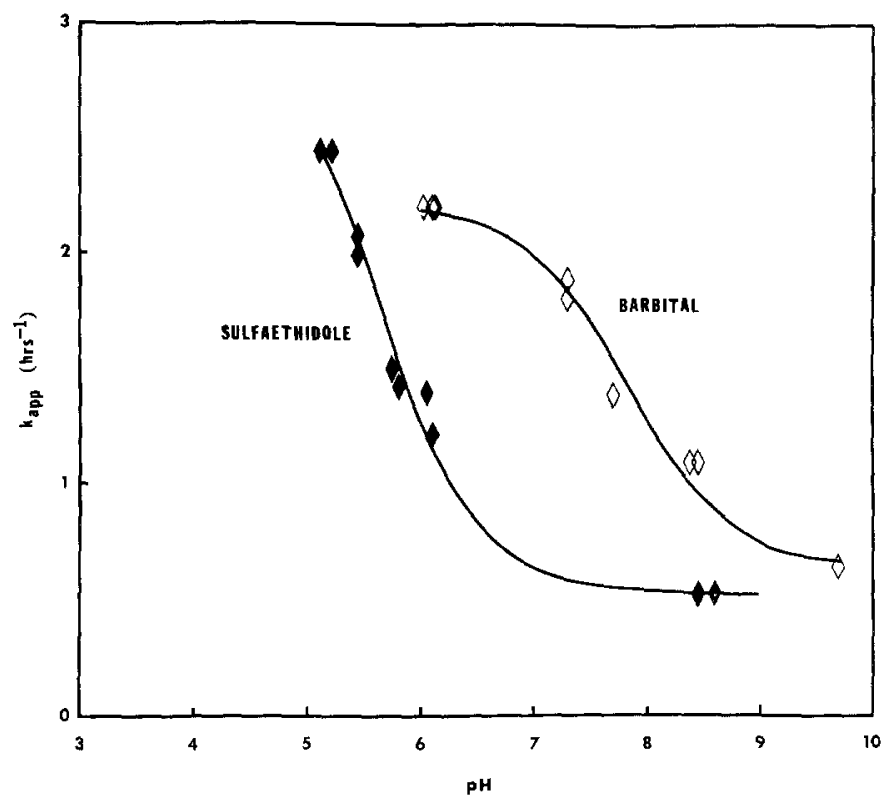

Fig. 5. Fit of the $k_{a p p}, p \mathrm{H}$ data of Crouthamel et al. (7) for barbital and sulfaethidole in rat small intestine to model $\mathrm{B}$, based on the parameters shown in Table V. 
degrees of freedom for the fitting of the barbital and sulfaethidole data, respectively. This may be inferred by comparing the magnitudes of the standard deviations in Table I to III with those in Table V. The problem of the relationship of the magnitude of experimental error, the number of degrees of freedom, and the magnitude of standard deviations of estimated parameters has been discussed by Atkins (26) and agrees with the above interpretation.

Suzuki et al. (4) reported that, when using their model, the diffusion coefficients for the barbiturates were smaller than those for the sulfonamides by a factor of 10 and that this could not easily be explained by the usual Stokes-Einstein diffusion equation. Based on diffusion theory, the $k_{u m}$ of models $A$ and $B$ in this report would be given by equation 60 :

$$
k_{\mathrm{um}}=\left(D_{\mathrm{um}} \cdot A\right) /(h \cdot V)
$$

where $D_{\text {um }}$ is the diffusion coefficient for the un-ionized acid out of the membrane, $A$ is the effective surface area of the membrane, $h$ is the effective thickness of the membrane-blood interface, and $V$ is the effective volume of

Table V. Estimated Parameters and Measures of Fit for Nonlinear LeastSquares Fitting of $k_{\mathrm{app}}, p \mathrm{H}$ Data for Crouthamel et al. (7) for Gastrointestinal Absorption of Barbital and Sulfaethidole in Rat Intestine to Model B (Equations 22 and 38)

\begin{tabular}{|c|c|c|c|c|}
\hline \multirow[b]{3}{*}{ Parameter } & \multicolumn{4}{|c|}{ Drug } \\
\hline & \multicolumn{2}{|c|}{ Barbital } & \multicolumn{2}{|c|}{ Sulfaethidole } \\
\hline & Estimate & $\mathrm{SD}^{a}$ & Estimate & $\mathrm{SD}$ \\
\hline$k_{\mathrm{um}}\left(\mathrm{hr}^{-1}\right)$ & $3.63^{b}$ & 11.0 & $5.82^{b}$ & 30.4 \\
\hline$k_{\text {im }}\left(\mathrm{hr}^{-1}\right)$ & $14.5^{c}$ & 1626.0 & $14.3^{c}$ & 1608.0 \\
\hline$P_{\text {im }}(1+1$ & 1.55 & 12.0 & 1.08 & 11.8 \\
\hline$P_{i}^{\mu}$ & 0.0475 & 1.56 & 0.0388 & 4.54 \\
\hline \multirow[t]{2}{*}{$p \mathrm{~K}_{a}$} & 7.44 & 1.45 & 5.33 & 4.22 \\
\hline & \multicolumn{4}{|c|}{ Measures of $\mathrm{fit}^{d}$} \\
\hline$r_{1}^{2}$ & \multicolumn{2}{|c|}{0.998} & \multicolumn{2}{|c|}{0.997} \\
\hline$r_{2}^{2}$ & \multicolumn{2}{|c|}{0.979} & \multicolumn{2}{|c|}{0.983} \\
\hline Corr. & \multicolumn{2}{|c|}{0.990} & \multicolumn{2}{|c|}{0.992} \\
\hline
\end{tabular}

${ }^{a}$ Standard deviation of estimated parameter. These are large in these fittings, since there were only nine data points for barbital and ten for sulfaethidole, providing only 4 and 5 degrees of freedom, respectively.

${ }^{b}$ The $k_{\text {um }}$ values of 3.63 and $5.82 \mathrm{hr}^{-1}$ correspond to values of 1.08 and $1.62 \mathrm{sec}^{-1} \times 10^{3}$, respectively.

'The $k_{\mathrm{im}}$ values of 14.5 and $14.3 \mathrm{hr}^{-1}$ correspond to values of 4.02 and $3.97 \mathrm{sec}^{-1} \times 10^{3}$, respectively.

${ }^{d}$ See footnotes to Table I. 
the membrane. Since barbital and sulfaethidole were studied in the rat under the same experimental conditions, the ratio of the $k_{\text {um }}$ values for these two compounds should equal the ratio of the diffusion coefficients. the ratio of $k_{u m}$ for barbital $/ k_{u m}$ for sulfaethidole is $3.63 / 5.82=0.62$, which appears to be a more reasonable ratio than that reported by Suzuki et al. (4).

In the footnotes to Table $\mathrm{V}$, the rate constants $k_{\text {um }}$ and $k_{\text {im }}$ for barbital and sulfaethidole are given with dimensions of $\sec ^{-1} \times 10^{3}$ for comparison with data given in Tables I to III. The values of $k_{\text {um }}$ of $7.48 \mathrm{sec}^{-1} \times 10^{3}$ for the $0-, m$-, and $p$-toluic acids, $7.12 \mathrm{sec}^{-1} \times 10^{3}$ for the $\mathrm{C}_{4}$ to $\mathrm{C}_{8} n$-alkanoic acids, and $6.78 \mathrm{sec}^{-1} \times 10^{3}$ for the $C_{9}$ to $C_{12} n$-alkanoic acids for buccal absorption in man are about seven times the $k_{\text {um }}$ value of $1.08 \mathrm{sec}^{-1} \times 10^{3}$ for barbital and about 4.3 times the $k_{\mathrm{um}}$ value of $1.62 \mathrm{sec}^{-1} \times 10^{3}$ for sulfaethidole in rat intestine. The $k_{\text {im }}$ value of $4.38 \mathrm{sec}^{-1} \times 10^{3}$ for buccal absorption of the $\mathrm{C}_{4}$ to $\mathrm{C}_{8} n$-alkanoic acids in man is very similar to the $k_{\text {im }}$ values of 4.02 and $3.97 \mathrm{sec}^{-1} \times 10^{3}$ for absorption of barbital and sulfaethidole, respectively, in rat small intestine. It is also of interest that the $P_{u}$ values of 1.55 and 1.08 for barbital and sulfaethidole, respectively, are closest to the value of $P_{u}$ of 1.21 for hexanoic acid (see $\mathrm{C}_{6}$ under model B in Table II).

\section{Relative Values of Intrinsic Partition Coefficients for Ions}

The $P_{i}$ values of 0.0475 and 0.0388 for barbital and sulfaethidole, respectively, in rat intestine are very similar to the $P_{i}$ values of 0.0409 , $0.0523,0.0523,0.0524$, and 0.0344 estimated for the $\mathrm{C}_{6}, \mathrm{C}_{7}, \mathrm{C}_{8}, \mathrm{C}_{9}$, and $\mathrm{C}_{10} n$-alkanoic acids, respectively, in the buccal absorption test. There is no uniform change in $P_{i}$ values with increase in the number of methylene groups of the $n$-alkanoic acids as for the $P_{u}$ values (see Fig. 4). The $P_{i}$ value for the $\mathrm{C}_{4}$ acid is extremely small, there is some increase for the $\mathrm{C}_{5}$ acid, then the $P_{i}$ values are essentially the same for the $\mathrm{C}_{7}$ through $\mathrm{C}_{10}$ acids, then there is an abrupt increase for the $C_{11}$ and $C_{12}$ acids (see Tables II and III). Fitting of the $\mathrm{C}_{4}$ through $\mathrm{C}_{8} n$-alkanoic acid data to model $\mathrm{B}$ resulted in improvement of fit by all three measures of fit (see Table II). Also, the $P_{u}$ values, estimated using model $A$, are all higher for the $C_{4}$ through $C_{8}$ acids and do not fall on the line, shown in Fig. 4, based on model B. These points suggest that absorption of ions should be taken into consideration for all the $n$-alkanoic acids studied so far.

The fact that the standard deviations of the estimated $P_{i}$ values are relatively much larger in Table II than in Table III is probably a reflection that in fitting the $\mathrm{C}_{4}$ through $\mathrm{C}_{8}$ acids to model $\mathrm{B}$ the data supplied little information about the asymptotic nature of $k_{\text {app }}$ at high $p \mathrm{H}$. 


\section{DISCUSSION}

\section{Treatment of Ion Absorption in Model B}

The buccal absorption data of the $o-, m$-, and $p$-toluic acids, evaluated in this report, can be explained solely on the basis of absorption of the unionized molecules. However, it seems unlikely that the buccal absorption data of the $n$-alkanoic acids (particularly the higher members, $\mathrm{C}_{9}$ to $\mathrm{C}_{12}$ ) and the gastrointestinal absorption data of barbital and sulfaethidole can be explained without invoking the concept that ions are absorbed. Attempts to fit the latter data to equations 17 and 22 were unsuccessful.

The investigations of Turner et al. (27), and the literature they summarized, indicate that certain ionized drugs do pass through the in vitro intestine of the rat. Recently, Lanman et al. (28) demonstrated first-order disappearance of the ions of hippuric acid, sulfanilic acid, phenol red, and $p$-aminohippuric acid from rat intestine in vivo, and they reported that the anions were absorbed at rates which ranked in the same order as the apparent chloroform/water partition coefficients measured at $\mathrm{pH}$ 7.4.

A conventional model is the aqueous pore-lipoid film model of biological membranes. According to this model, most of the diffusion occurs through the lipoid film with hydraulic flow passing through the channels, either intracellular or intercellular (29). Past investigations (30-32) have indicated that there is apparently a species difference in the size of the pores or channels. Höber and Höber (30) reported that in the rat only small molecules, with molecular weight about 180 or less (corresponding to a molecular radius of about $4 \AA$ ) diffuse through water-filled pores. Lifson and Hakim (31) estimated a functional pore radius of 10 to $15 \AA$ in the dog. Fordtran et al. (32) estimated the effective pore radius to be 7 to $8.5 \AA$ in the jejunum and 3.0 to $3.8 \AA$ in the ileum of the human small intestine. One could assume that small organic ions are absorbed through water-filled pores or channels in an analogous manner to the non-lipid-soluble small molecules studied in the previous investigations (30-32). However, if the effective pore diameter in the buccal membrane of man is assumed to be of the same order of magnitude as those estimated by Fordtran et al. (32) in the human small intestine, one would not expect the large anions of the higher $n$-alkanoic acids to be absorbed in this manner. Also, the data of Beckett and Moffat (20) strongly suggest a disproportionate but gradual increase in absorption of ions as the nalkanoic acid series is ascended. We thus chose an alternative to the pore theory to account for ion absorption.

Vacek et al. (33) studied the paper chromatographic behavior of a series of chlorophenols using Whatman No. 3 paper impregnated with $10 \%$ olive oil in benzene and buffers of different $p \mathrm{H}$ as the mobile phase. They found that at low $p \mathrm{H}$ values, the $R_{F}$ value (in our symbolism) was given by 
equation 61 :

$$
R_{F}=1-f_{E}=1 /\left(1+f_{u} P_{u}^{\prime}\right)
$$

where $P_{u}^{\prime}$ is given by equation 5 except that the volume ratio is replaced by the areas of cross-section of both phases on the paper. It should be noted that equation 61 is readily obtained from equation 20 . However, to explain the chromatographic behavior of the chlorophenols when $p \mathrm{H}>p \mathrm{~K}_{a}$, the authors had to define a distribution coefficient for the anions and derive an equation, which in our symbolism is equation 62 and which is readily obtained from equation 40 :

$$
R_{F}=1-f_{E}=1 /\left[1+f_{u} P_{u}^{\prime}+\left(1-f_{u}\right) P_{i}^{\prime}\right]
$$

where $P_{i}^{\prime}$ is given by equation 28 , except that the volume ratio is replaced by the areas of cross-section of both phases on the paper. In relating the equations above to the equations for model $\mathrm{B}$, it is implicit that olive oil in the in vitro chromatographic system is analogous to the membrane.

In deriving the equations for model $\mathrm{B}$, we chose to treat ion absorption in vivo as a partitioning process analogous to the in vitro chromatographic system of Vacek et al. (33). This implies that the organic ions partition into the membrane and transfer out of the membrane in an analogous manner to that of the un-ionized molecules, but the exact mechanism is not specified by the theory. This assumption is supported by the results and correlation of Lanman et al. (28) and the opinion expressed by Beckett and Moffat (20) with respect to the higher $n$-alkanoic acids. Ling (34) conceives that the gastrointestinal membrane consists largely of water and that the water in the cell is adsorbed as polarized multilayers on the proteins, which lowers the activity of water within the cell. This treatment suggests that the membrane does not really have the character of a nonpolar "oil" or organic solvent, as has frequently been assumed in the past, but that it may be much more polar. Partitioning of organic ions into such a membrane appears reasonable.

The possibility of ion-pair absorption also exists for some drugs. Investigations of Perrin and Vallner (35) and Suzuki et al. (36) strongly suggest that ion-pair absorption occurs with some amphoteric and basic drugs. The paper of Doyle and Levine (37) suggests how equation 38 would have to be modified to incorporate absorption of ion pairs in vivo.

\section{Omission of Consideration of One of the Aqueous Diffusion Layers}

The existence of the aqueous diffusion layer or unstirred water layer on the lumen side of gastrointestinal and buccal membranes is not denied by our treatment, but rather just not taken into consideration. Several recent articles have discussed the possible role of the unstirred water layer in 
membrane transport (38-42). The models of Suzuki et al. (4), Ho and Higuchi (5), Ho et al. (46), and Flynn and Yalkowsky (43) incorporated a consideration of the aqueous diffusion layer in absorption and transport through membranes in vitro. Wilson et al. (40) studied the uptake of bile acid and fatty acid from monomer solutions and of fatty acid from micellar solutions across the rat jejunal brush border. They concluded that during the absorption of these substances from monomer solutions the cell membrane primarily is rate-limiting, while when the fatty acid is dissolved in a bulky micelle the diffusion of the large micelle across the unstirred layer is rate-limiting. The in vivo data evaluated in this report all arose from administration of drugs in monomer solutions. Although our derivations disregard the aqueous diffusion layer on the lumen side of the membrane, they do not necessarily disregard the aqueous diffusion layer on the blood side of the membrane. The assumption is that the rate-limiting step is transport out of the membrane into the systemic circulation and that this is independent of the partition coefficient. This is different than the treatment of Davson and Danielli (45) and appears to make the treatment unique. Although the mechanism is not specified, transport out of the membrane could involve the aqueous diffusion layer on the blood side of the membrane. It is of interest that the models of Suzuki et al. (4), Ho and Higuchi (5), and Ho et al. (46) disregard the aqueous diffusion layer on the blood side of the membrane but take into consideration the aqueous diffusion layer on the lumen side of the membrane.

\section{Comparison of Estimated $p \mathrm{~K}_{a}$ 's from in vivo Data with Those Determined in vitro}

Table VI compares the $p \mathrm{~K}_{a}$ 's estimated by fitting the $k_{\text {app }}, p \mathrm{H}$ data obtained in vivo at $37^{\circ} \mathrm{C}$ with the $p \mathrm{~K}_{a}$ 's determined in vitro at $25^{\circ} \mathrm{C}$. With two exceptions, namely, $o-$ and $m$-toluic acids, the in vitro $p \mathrm{~K}_{a}$ is higher than the estimated in vivo $p \mathrm{~K}_{a}$. Temperature, alone, has variable effects on the $p \mathrm{~K}_{a}$ measured in vitro (47). The differences in $p \mathrm{~K}_{a}$, shown in Table VI, may be expected on the basis of ionic strength, salt effects, colloidal effects, etc. (48), and experimental error in fitting the $k_{\text {app }}, p \mathrm{H}$ data.

\section{CONCLUSIONS}

The new physical models, embodied in equations 17,22 , and 38 of this report, appear to be equally as successful, if not more successful than the aqueous diffusion layer models of Suzuki et al. (4), Ho and Higuchi (5), and Ho et al. (46) in analyzing gastrointestinal and buccal absorption data so far collected in animals and man. This does not imply that one theory is correct and 
Table VI. Comparison of Estimated $p K_{a}$ 's from in Vivo Data $\left(37^{\circ} \mathrm{C}\right)$ with Those Determined in Vitro $\left(25^{\circ} \mathrm{C}\right)$

\begin{tabular}{lcccr}
\hline \multicolumn{1}{c}{ Compound } & Model & $\begin{array}{c}\text { Estimated from } \\
\text { in vivo data }\left(37^{\circ} \mathrm{C}\right)\end{array}$ & In vitro $\left(25^{\circ} \mathrm{C}\right)$ & $\Delta p \mathrm{~K}_{a}{ }^{d}$ \\
\hline o-Toluic acid & $\mathrm{A}$ & 4.04 & $3.92^{a}$ & -0.12 \\
m-Toluic acid & $\mathrm{A}$ & 4.26 & $4.24^{a}$ & -0.02 \\
$p$-Toluic acid & $\mathrm{A}$ & 4.27 & $4.33^{a}$ & 0.06 \\
$\mathrm{C}_{4}-\mathrm{C}_{8}$ n-alkanoic acids & $\mathrm{A}$ & 4.60 & $4.84^{b}$ & 0.24 \\
$\mathrm{C}_{9}-\mathrm{C}_{12}$ - & $\mathrm{B}$ & 4.74 & $4.84^{b}$ & 0.10 \\
Barbanoic acids & $\mathrm{B}$ & 4.67 & $4.84^{b}$ & 0.17 \\
Sulfaethidole & $\mathrm{B}$ & 7.44 & $7.9^{c}$ & 0.46 \\
\hline
\end{tabular}

${ }^{a}$ Reported by Beckett and Moffat (20).

${ }^{b}$ The average of $p \mathrm{~K}_{a}$ 's of 4.82 for $n$-butyric acid and 4.85 for $n$-octanoic acid cited by Beckett and Moffat (20).

${ }^{c}$ Reported by Crouthamel et al. (7).

${ }^{d}$ Difference between in vitro $p \mathrm{~K}_{a}$ at $25^{\circ} \mathrm{C}$ and estimated in vivo $p \mathrm{~K}_{a}$ at $37^{\circ} \mathrm{C}$.

the other incorrect. To the authors, it implies that the appropriate model cannot be chosen on the basis of the type of data which have been collected to date and that we need more definitive data to make a decision. In essence, the new equations quantitate the $p \mathrm{H}$-partition hypothesis $(1,2)$. They could also allow quantitation of renal reabsorption of acids and bases.

\section{ACKNOWLEDGMENTS}

The authors are grateful to Dr. Walter Morozowich, The Upjohn Company, Kalamazoo, Michigan, who originally interested us in extraction theory and supplied many of the early references. Although he declined to be a coauthor of this paper, his valuable contributions were greatly appreciated. The authors are also grateful to Dr. Carl Metzler, The Upjohn Company, for use of the program NONLIN.

\section{REFERENCES}

1. P. A. Shore, B. B. Brodie, and C. A. M. Hogben. The gastric secretion of drugs: A $p \mathrm{H}$ partition hypothesis. J. Pharmacol. Exptl. Therap., 119, 361-369 (1957).

2. C. A. M. Hogben, D. J. Tocco, B. B. Brodie, and L. S. Schanker. On the mechanism of intestinal absorption of drugs. J. Pharmacol. Exptl. Therap., 125, 275-282 (1959).

3. T. Koisumi, T. Arita, and K. Kakemi. Absorption and excretion of drugs. XIX. Some pharmacokinetic aspects of absorption and excretion of sulfonamides. (1) Absorption from rat stomach. Chem. Pharm. Bull., 12, 413-420 (1964).

4. A. Suzuki, W. I. Higuchi, and N. F. H. Ho. Theoretical model studies of drug absorption and transport in the gastrointestinal tract. I and II. J. Pharm. Sci., 59, 644-651 and 651-659 (1970).

5. N. F. H. Ho and W. I. Higuchi. Quantitative interpretation of in vivo buccal absorption of $n$-alkanoic acids by the physical model approach. J. Pharm. Sci., 60, 537-541 (1971). 
6. J. G. Wagner. Biopharmaceutics and Relevant Pharmacokinetics, Drug Intelligence Publications, Hamilton Press, Hamilton, Ill., 1971, p. 36.

7. W. G. Crouthamel, G. H. Tan, L. W. Dittert, and J. T. Doluisio. Drug absorption. IV. Influence of $p \mathrm{H}$ on absorption kinetics of weakly acid drugs. J. Pharm. Sci., 60, 1160-1163 (1971).

8. G. H. Mudge and I. M. Weiner. Renal excretion of weak organic acids and bases. In C. A. M. Hogben (ed.), Vol. IV, Drug and Membranes, Macmillan, New York, 1963, pp. 157-164.

9. T. Koisumi, T. Arita, and K. Kakemi. Absorption and excretion of drugs. XXI. Some pharmacokinetic aspects of absorption and excretion of sulfonamides. (3) Excretion from the kidney. Chem. Pharm. Bull., 12, 428-432 (1964).

10. R. B. Conn, A. J. Sabo, D. Lander, and J. Y. L. Ho. Inconstancy of renal clearance values with changing plasma concentrations. Nature, 203, 143-146 (1964).

11. E. Krüger-Thiemer and P. Bünger. Experimental studies and clinical experience-the assessment of risk. Excerpta Medica International Congress Series No: 97, Proceedings of the European Series for the Study of Drug Toxicity, Meeting in Stockholm, Sweden, June 1965, Vol. VI, Excerpta Medica Foundation, 1965, pp. 185-207.

12. J. G. Wagner. Equations for excretion rate and renal clearance of exogenous substances which are not actively reabsorbed. J. Clin. Pharmacol., 7, 89-92 (1967).

13. A. H. Beckett, R. N. Boyes, and G. T. Tucker. Use of the analogue computer to examine the quantitative relation between urinary $p \mathrm{H}$ and kidney reabsorption of drugs partially ionized at physiological $p \mathrm{H}$. J. Pharm. Pharmacol., 20, 269-276 (1968).

14. A. H. Beckett, R. N. Boyes, and G. T. Tucker. Use of the analogue computer to predict the distribution and excretion of drugs under conditions of fluctuating urinary $p \mathrm{H} . J$. Pharm. Pharmacol., 20, 277-282 (1968).

15. K. Kakemi, T. Arita, R. Hori, and R. Konshi. Absorption and excretion of drugs. XXX. Absorption of barbituric acid derivatives from rat stomach. Chem. Pharm. Bull., 15, 1534-1539 (1967).

16. K. Kakemi, T. Arita, S. Muranishi, and H. Matsui. Absorption and excretion of drugs. XXVIII. Rectal absorption of sulfonamides from oily solutions. J. Pharm. Soc. Japan, 86, 279-282 (1966).

17. K. Kakemi, T. Arita, R. Hori, and R. Konishi. Absorption and excretion of drugs. XXXII. Absorption of barbituric acid derivatives from rat small intestine. Chem. Pharm. Bull., $15,1883-1887$ (1967).

18. A. H. Beckett and E. J. Triggs. Buccal absorption of basic drugs and its application as an in vivo model of passive drug transfer through lipid membranes. J. Pharm. Pharmacol., 19, 31S-41S (1967) (Suppl.).

19. A. H. Beckett, R. N. Boyes, and E. J. Triggs. Kinetics of buccal absorption of amphetamines. J. Pharm. Pharmacol., 20, 92-97 (1968).

20. A. H. Beckett and A. C. Moffat. The influence of alkyl substitution in acids on their performance in the buccal absorption test. J. Pharm. Pharmacol., 20, 239S-247S (1968).

21. L. C. Craig. Identification of snall amounts of organic compounds by distribution studies. Application to atabrine. J. Biol. Cheni., 150, 33-45 (1943).

22. C. Golumbic, M. Orchin, and S. Weller. Partition studies on phenols. I. Relation between partition coefficient and ionization constant. J. Am. Chem. Soc., 71, 2624-2627 (1949).

23. C. Golumbic and M. Orchin. Partition studies. V. Partition coefficients and ionization constants of methyl-substituted pyridines and quinolines. J. Am. Chem. Soc., 72, 4145-4147 $(1950)$.

24. P. L. Davis and P. K. Smith. Relation of rate of excretion of salicylate to urinary acidity. Arch. Int. Pharmacodyn., 86, 303-310 (1951).

25. G. Levy, T. Tsuchiya, and L. P. Amsell. Limited capacity for salicyl phenolic glucuronide formation and its effect on the kinetics of salicylate elimination in man. Clin. Pharmacol. Therap., 13, 258-268 (1972).

26. G. L. Atkins. Multicompartment Models for Biological Systems, Methuen, London, 1969, pp. 99-101. 
27. R. H. Turner, C. S. Mehta, and L. Z. Benet. Apparent directional permeability coefficients for drug ions: In vitro intestinal perfusion studies. J. Pharm. Sci., 59, 590-595 (1970).

28. R. C. Lanman, C. E. Stremsterfer, and L. C. Schanker. Absorption of organic anions from the rat small intestine. Xenobiotica, 1, 613-619 (1971).

29. R. Höber. Physical Chemistry of Cells and Tissues, Blakiston Press, Philadelphia, 1945, p. 540.

30. R. Höber and J. Höber. Experiments on the absorption of organic solutes in the small intestine of rats. J. Cell. Comp. Physiol., 10, 401-422 (1937).

31. N. Lifson and A. A. Hakim. Simple diffusive-convective model for intestinal absorption of a nonelectrolyte (urea). Am. J. Physiol, 211, 1137-1146 (1966).

32. J. S. Fordtran, F. C. Rector, Jr., M. F. Ewton, M. Soter, and J. Kinney. Permeability characteristics of the human small intestine. J. Clin. Invest., 44, 1935-1944 (1965).

33. Z. Vacek, F. Štota, and J. Staněk. $p \mathrm{H}$-chromatography of chlorinated phenols. J. Chromatog., 19, 572-579 (1965).

34. G. N. Ling. A new model for the living cell: A summary of the theory and recent experimental evidence for its support. Internat. Rev. Cytol., 26, 1-59 (1969).

35. J. H. Perrin and J. J. Vallner. The effect of the anion on the absorption of tetracycline from the rat stomach. J. Pharm. Pharmacol., 22, 758-762 (1970).

36. E. Suzuki, M. Tsukigi, S. Muranishi, H. Sezaki, and the late K. Kakemi. The absorption from the gut of quinine and chlorpheniramine given with various anionic agents. J. Pharm. Pharmacol., 24, 138-144 (1972).

37. T. D. Doyle and J. Levine. Application of ion-pair extraction to partition chromatographic separation of pharmaceutical amines. Anal. Chem., 39, 1282-1287 (1967).

38. A. W. Cuthbert and Y. Dunant. Diffusion of drugs through stationary water layers as the rate limiting process in their action at membrane receptors. Brit. J. Pharmacol., 40, 508-521 (1970).

39. J. M. Dietschy, V. L. Salee, and F. A. Wilson. Unstirred water layers and absorption. across intestinal mucosa. Gastroenterology, 61, 932-934 (1971).

40. F. A. Wilson, V. L. Salee, and J. M. Dietschy. Unstirred water layers in intestine: Rate determinant of fatty acid absorption from micellar solutions. Science, 174, 1301-1303 (1971).

41. D. M. Miller. The effect of unstirred layers on the measurement of transport rates in individual cells. Biochim. Biophys. Acta, 266, 85-90 (1972).

42. R. E. Beck and J. S. Schultz. Hindrance of solute diffusion within membranes as measured with microporous membranes of known pore geometry. Biochim. Biophys, Acta, 255, 273-303 (1972).

43. G. L. Flynn and S. H. Yalkowsky. Correlation and prediction of mass transport across membranes. I. Influence of alkyl chain length on flux-determining properties of barrier and diffusant. J. Pharm. Sci., 61, 838-852 (1972).

44. I. M. Weiner and G. H. Mudge. Renal tubular mechanisms for excretion of organic acids and bases. Am. J. Med., 36, 743-762 (1964).

45. H. Davson and J. F. Danielli. Permeability of Natural Membranes, Cambridge University Press, New York, 1952, Chap. 5, Appendix A, pp. 48-56 and 324-335.

46. N. F. H. Ho, W. I. Higuchi, and J. Turi. Theoretical model studies of drug absorption and transport in the G I tract. III. J. Pharm. Sci., 61, 192-197 (1972).

47. R. C. Weast (ed. in chief). Handbook of Chemistry and Physics, 45th ed., Chemical Rubber Co., Cleveland, 1964, p. D-79.

48. G. H. A. Clowes, A. K. Keltch, and M. E. Krohl. Extracellular and intracellular hydrogen ion concentration in relation to anesthetic effects of barbituric acid derivatives. J. Pharmacol. Exptl. Therap., 68, 312-329 (1940). 